\title{
Altered acetylcholinesterase activity (AChE) and maze performance of developing rats (Rattus norvegicus) following mesencephalic electrical brain stimulation
}

\author{
GEORGE A. LEWIS, SHELDON H. PRESKORN, and CARROLL W. HUGHES \\ Wichita State University, Wichita, Kansas 67208
}

\begin{abstract}
Cortical arousal was altered by electrical brain stimulation (EBS) to the mesencephalic ascending reticular formation beginning at 27 days of age and administered $2 \mathrm{~h} /$ day for either 14 or 28 days. Subjects receiving brain stimulation from 27 to 41 days of age showed a significant decrease in telencephalon AChE activity and weight when compared to controls. These decreases in biochemical and physical parameters corresponded to a marked decrement in maze performance. The advantages and potential uses of the weanling chronic EBS preparation to investigate critical developmental periods are considered.
\end{abstract}

Environmental modification of ontogenetic development during sensitive phases has been demonstrated to affect learning ability later in life (Denenberg, Woodcock, \& Rosenberg, 1968; Forgays \& Forgays, 1952; Thompson \& Melzack, 1956). Evidence for the functional significance of central cholinergic transmitter activity in differential learning ability has likewise been reported (Krech, Rosenzweig, \& Bennett, 1962; Rosenzweig \& Bennett, 1969). A major problem with this latter research has been that subjects raised in "deprived" vs. "enriched" environments are exposed to less specific learning experiences while also receiving less sensory excitation with presumably less resultant cortical arousal. Thus, it has not been possible to distinguish the relative effects of specific learning experiences vs. cortical arousal on later biochemical and behavioral measures.

The present research attempted to circumvent this problem by modifying cortical arousal without concomitantly exposing the subjects to different environments (Lewis, Preskorn, \& Hughes, Note 1). Electrical brain stimulation (EBS) to the mesencephalic ascending reticular formation during an early critical developmental period was used to produce an altered level of cortical arousal in experimental subjects when compared to controls. Measures of AChE activity

This research is published posthumously in honor of Dr. George Lewis, who conceived it. Dr. Lewis, more importantly, was an outstanding teacher and an immense source of inspiration and encouragement to all who knew him. S. H. Preskorn is currently at Washington University, Department of Psychiatry, School of Medicine, 4940 Audubon Avenue, St. Louis, Missouri 63110. C. W. Hughes is now at the University of Missouri, Psychology Section, H-SS Building, Rolla, Missouri 65401. Send requests for reprints to Carroll W. Hughes, Ph.D. and maze performance were taken following the conclusion of EBS. A unique consideration of this study was the use of chronically implanted electrodes in weanling rats (Hughes, Lewis, \& Preskorn, 1973).

\section{METHOD}

\section{Subject Preparation}

Male Sprague-Dawley rats (Rattus norvegicus) arrived at the laboratory at 22 days of age. Stainless steel Teflon-coated bipolar electrodes (.008 [MS303] Plastic Products Co.) were implanted stereotaxically into the dorsal ascending midbrain reticular formation on Day 23 or Day 24. Electrode placement was made according to a previously determined skull reference point $(0.5 \mathrm{~mm}$ anterior to the lambdoidal suture and $0.5 \mathrm{~mm}$ lateral to the sagittal suture), and the electrode tip was lowered $5.6 \mathrm{~mm}$ below the dura. Preliminary studies had demonstrated histologically that this procedure resulted in electrode tip placement just medial to the brachium of the inferior colliculus (Hughes et al., 1973). Since some electrode mounts came loose as the skull continued to mature, sufficient animals were prepared so that 70 healthy, permanently implanted subjects were obtained. These animals were assigned randomly to six groups, and EBS or sham EBS was begun at 27 days of age. Groups 1 through 5 had 13 subjects each and Group 6 had 5 subjects. Group 1 received 14 days of EBS, and Group 3 received 28 days of EBS. Groups 2 (14-day sham EBS) and 4 (28-day sham EBS) were sham EBS controls. Group 5 received 14 days of EBS followed by 14 days of sham EBS. Groups 1-5 were placed on 23-h food deprivation for the last 6 days of EBS or sham EBS in preparation for the behavioral testing that followed. Group 6 received 28 days of EBS with no food deprivation to assess the possible effects of food deprivation on biochemical activity.

\section{Electrical Stimulation}

The EBS subjects received $1.5 \mu \mathrm{A}$ stimulation for a 2 -h period daily with a Lafayette (Model A 800 ) $60-\mathrm{Hz}$ full sine-wave stimulator. The stimulator alternated between $10 \mathrm{sec}$ on and $10 \mathrm{sec}$ off. The subjects were attached to tension leads and remained in their home cages during the stimulation period. Recent work with cats by Webster, Sagvolden, Saunders, and Monkvik (1974) suggests that centrally located "nonspecific" structures of the 
brainstem are markedly resistant to habituation when stimulated in this fashion. Sham EBS subjects were attached to the stimulator in the same manner as EBS subjects but received no electrical stimulation. The animals in Groups 1-5 were randomly subdivided into groups that contained eight subjects for behavioral testing and five subjects for biochemical analyses. All tests were initiated 1 day following termination of EBS.

\section{Open Field}

Open-field measures were taken in an arena that was $114.3 \times$ $114.3 \times 45.7 \mathrm{~cm}$, with the floor marked off in $22.9-\mathrm{cm}$ squares. Subjects were placed in the open field for 9 min each morning for 3 days before any other laboratory activity occurred, with the order of testing counterbalanced. Each 9-min session was divided into 3-min segments for data analysis. The raw score represented the number of squares entered during each time segment.

\section{Krech Solvable Maze}

Upon completion of Day 3 of open-field testing, subjects received one-way door training and $30 \mathrm{~min}$ of exploratory experience in the Krech maze (Krech et al., 1962). Subjects were run eight trials per day, and running order was counterbalanced. The first problem was visual, with the lighted alleys signifying the unlocked doors. The light sequence was changed prior to each trial according to a prearranged sequence such that the right and left side of each choice point was lighted an equal number of times. A criterion of three or fewer errors (entering a blocked doorway) in eight trials was set, with a minimum of 4 days in the visual task.

The day after reaching criterion on the visual problem, a spatial problem was begun. For all trials, the locked doors were in a constant pattern (left-right-left-left), and the light sequence remained as it was in the visual problem. The criterion was identical to that of the visual problem. Data for the visual and spatial problems were number of errors to criterion and the number of days on each problem.

\section{Biochemical Analyses}

The entire brain, excluding the olfactory bulbs, was removed following decapitation. The brains were divided into the telencephalon and brainstem by free-hand dissection. The two samples were weighed separately, frozen on dry ice within $5 \mathrm{~min}$ of death, and stored at $-10^{\circ} \mathrm{C}$.

AChE activity was determined colorimetrically, using a modfification of the assay described by Ellman, Courtney, Androes, and Featherstone (1961). Acetylthiocholine was used as the substrate for the enzyme present in the biologic sample. The substrate is hydrolyzed to thiocholine when it reacts with dithiobisnitrobenzoate (DNTB) ion. The rate of production is measured by following the increase of yellow color at $412 \mathrm{~m} \mu$ in a photometer. The brain was homogenized in a solution of $20 \mathrm{mg}$ of tissue per milliliter of phosphate buffer ( $\mathrm{pH} 8.0,0.1 \mathrm{M}$ ). Tissue remaining in suspension after decanting from the homogenizer was removed by centrifuging the solution at $9,000 \mathrm{rpm}$ for $20 \mathrm{~min}$ and again decanting. A $0.4-\mathrm{ml}$ aliquot of the homogenate plus $100 \mu \mathrm{l}$ of the DNTB reagent were added to a cuvette containing $2.6 \mathrm{ml}$ of the phosphate buffer. Then $20 \mu \mathrm{l}$ of the acetylthiocholine substrate was added. All preparations and weighings, except for the actual colorimetric determinations, were done in a cold room at $4^{\circ} \mathrm{C}$. Absorbance readings were taken at 30,90 , and $150 \mathrm{sec}$.

This method enabled AChE activity to be determined in moles substrate hydrolyzed per minute per gram of tissue by the equation:

$$
R=5.74\left(10^{-4}\right) \frac{\Delta A}{C_{o}}
$$

where $\Delta \mathrm{A}=$ change in absorption per minute, $\mathrm{C}_{\mathrm{o}}=$ original concentration of tissue $(\mathrm{mg} / \mathrm{ml})$, and $5.74\left(10^{-4}\right)=$ the extinction coefficient of the yellow anion product.

Assays of lactic dehydrogenase (LDH) were made to provide an indication of possible changes in general metabolic rate due to the EBS treatment. LDH was assayed using the colorimetric procedure described by Neilands (1955) with the following modifications. In place of $0.5 \mathrm{M}$ sodium lactate, a commercial $0.5-\mathrm{M}$ lithium L-lactate was used; absorption readings were taken at 0 , 30 , and $90 \mathrm{sec}$. This provided a measure of LDH activity in moles substrate hydrolyzed per minute per gram tissue.

All assays were performed with a Beckman DU spectrophotometer with a water bath at $30^{\circ} \mathrm{C}$.

\section{Histology}

Subjects from the behavioral testing groups were used for histological examinations to determine EBS damage and to verify accurate placements of electrodes. Lesions were produced in subjects by delivering $1.5 \mathrm{~mA}$ for $20 \mathrm{sec}$ using a Lehigh Valley dc lesioner. Brains were perfused with Formalin and fixed in parlodion blocks for sectioning. Sections $(20 \mu)$ were thionine stained and the lesions noted.

\section{RESULTS}

\section{Histology}

Electrode tips were clustered around a point $1.75 \mathrm{~mm}$ lateral to the midline, $1 \mathrm{~mm}$ anterior to the interaural line, and $5.0 \mathrm{~mm}$ below the dura (König \& Klippel, 1963). In all cases, the electrode tip was within the dorsal reticular formation (Hughes et al., 1973).

\section{Behavioral Tests}

Open field. Analysis of variance (Winer, 1971) of the open-field scores indicated that days differed, with the least activity occurring on Day $1[F(2,70)$ $=12.6, \mathrm{p}<.001]$, and a decrease in activity as measured by 3 -min blocks within each daily period also occurred $[F(6,210)=68.6, p<.001]$. However, there was no effect for the 14- vs. 28-day treatment or EBS vs. sham, suggesting no general changes in activity between groups as assessed by this measure.

Krech solvable maze. Six different measures were analyzed as a test of more complex behavioral functioning. A one-way analysis of variance for each measure indicated only the number of days on the visual task to be significant $[\mathrm{F}(4,35)=3.1, \mathrm{p}<.05]$. However, no significant difference between individual means was found (Newman-Keuls, $p>.01$ ). A 2 by 2 analysis of variance (14 vs. 28 days, EBS vs. sham) was also made for each of the six measures. Two interactions indicated that 14-day EBS subjects took more total days and made more total errors than 14-day sham subjects $[\mathrm{F}(1,28)=4.6$ and 5.2 , respectively, $\mathrm{p}<.05$ ], while 28-day EBS subjects did not differ from 28-day sham subjects. The scores for 28-day subjects were intermediate to the two 14-day-group scores. Tests for simple main effects indicated that it was only the 14-day EBS group which differed. As Table 1 indicates, the means for the 14-day EBS group are comparable to the 14-day sham group.

\section{Biochemical Analyses}

A 6 by 2 (groups and telencephalon vs. brainstem sample) analysis of variance was used for AChE, 
Table 1

Behavioral Test Scores for the Krech Maze

\begin{tabular}{|c|c|c|c|c|c|c|}
\hline \multirow[b]{2}{*}{ Group } & \multicolumn{3}{|c|}{ Mean Number of Days } & \multicolumn{3}{|c|}{ Mean Number of Errors } \\
\hline & Visual & Spatial & Total & Visual & Spatial & Total \\
\hline $\begin{array}{l}\text { 14-day EBS } \\
\text { 14-day Sham } \\
\text { 28-day EBS } \\
\text { 28-day Sham } \\
\text { 14-day EBS/14-day Sham }\end{array}$ & $\begin{array}{l}5.9(.48) \\
4.5(.27) \\
4.5(.19) \\
4.1(.12) \\
5.6(.78)\end{array}$ & $\begin{array}{l}6.3(.62) \\
5.0(.63) \\
6.5(.71) \\
7.8(.92) \\
7.5(1.1)\end{array}$ & $\begin{array}{r}12.1(.77) \\
9.5(.71) \\
11.0(.78) \\
11.9(.99) \\
13.1(1.3)\end{array}$ & $\begin{array}{l}42.9(6.6) \\
24.6(2.3) \\
34.0(3.1) \\
31.3(4.4) \\
39.0(9.2)\end{array}$ & $\begin{array}{l}70.0(7.3) \\
55.7(7.5) \\
62.6(6.0) \\
75.5(9.5) \\
76.1(10.1)\end{array}$ & $\begin{array}{r}112.9(7.7) \\
80.4(7.8) \\
96.6(7.5) \\
106.7(13.1) \\
115.1(15.1)\end{array}$ \\
\hline
\end{tabular}

Note-Numbers in parentheses indicate standard error of the mean.

LDH, and brain weight (Table 2). Newman-Keuls comparisons were made where necessary at the .01 level.

AChE. Significant differences were found between telencephalon and brainstem $[\mathrm{F}(9,24)=4.1, \mathrm{p}<.01]$, indicating greater brainstem AChE activity. Group differences were also significant $[F(5,24)=17.3$, $\mathrm{p}<.001$ ]. Individual comparisons of telencephalon AChE activity indicated that the 14-day EBS subjects had significantly lower AChE activity than all others. Similarly, the 14-day EBS/14-day sham group had significantly less AChE activity than the 28-day EBS and 28-day sham groups. The non-food-deprived Group 6 (28-day EBS) did not differ from Group 3 (food-deprived 28-day EBS) on any of the biochemical measures.

LDH. The telencephalon LDH activity was greater than the brainstem rate $[\mathrm{F}(9,24)=3.8, \mathrm{p}<.01]$. A main effect for groups was found $[F(5,24)=$ $4.3, p<.01$ ], but none of the individual comparisons was significant.

\section{Brain Weight}

The telencephalon weights of subjects receiving 14 days of EBS were significantly less than the telencephalon weight of all the other groups $[F(5,24)=$ $14.4, \mathrm{p}<.001]$. No other comparisons were significant. ${ }^{1}$

\section{DISCUSSION}

This experiment was designed to test the postulate that brain AChE activity, especially telencephalon activity, is positively correlated with maze performance. In examining this question, we attempted to avoid the problem of specific learning contamination by altering AChE values with EBS to the reticular formation. Previous researchers have demonstrated that EBS applied to certain areas of the reticular formation results in electroencephalographic (EEG) desynchronization (Meyer, Monvra, Sakamoto, \& Kondo, 1969; Moruzzi \& Magoun, 1949) and the release of acetylcholine (ACh) from cortical areas (Collier \& Murray-Brown, 1968; Kanai \& Szerb, 1965; Phillis, 1968). In this study, reticular formation EBS resulted in reduced telencephalon AChE activity. The original hypothesis is supported by the fact that the reduced AChE activity produced by early EBS corresponded with a decrement in maze performance.

In evaluating the data for significant interactions, we examined the effect of chronic EBS on the animal's general activity level and nutritional state and whether or not EBS was aversive. It is conceivable that EBS might have produced either hyperactive or motor-retarded animals and, thus, adversely affected their maze performance. However, there was no significant difference between any groups on the open-field measure (or LDH). Thus, EBS did not affect the gross motor activity. Consequently, the maze performance differences cannot be attributed to such an effect. Another conceivable possibility was that EBS may have somehow interfered with the normal growth of the subjects, which resulted in stunted animals. Comparison of the total body weights of the EBS subjects to their appropriate controls revealed no such significant differences.

Table 2

Mean Values for Brain Weight and Biochemical Measures

\begin{tabular}{|c|c|c|c|c|c|c|}
\hline \multirow[b]{2}{*}{ Group } & \multicolumn{2}{|c|}{ Brain Weight (g) } & \multicolumn{2}{|c|}{ AChE* } & \multicolumn{2}{|c|}{ LDH* $^{*}$} \\
\hline & $\mathrm{T}$ & B & $\mathbf{T}$ & B & $\mathrm{T}$ & B \\
\hline 14-day EBS & $.38(.02)$ & $1.07(.03)$ & $63.3(7.9)$ & $165.7(10.4)$ & $105.2(10.1)$ & $85.8(4.0)$ \\
\hline 14-day Sham & $.81(.01)$ & $.81(.03)$ & $166.5(7.4)$ & $206.8(7.1)$ & $93.8(4.7)$ & $82.2(2.6)$ \\
\hline 28-day EBS & $.82(.03)$ & $.87(.05)$ & $198.9(11.8)$ & $192.1(7.7)$ & $92.2(4.3)$ & $79.9(4.7)$ \\
\hline 28-day Sham & $.82(.03)$ & $.87(.03)$ & $192.9(19.4)$ & $211.2(14.1)$ & $84.4(5.1)$ & $73.1(5.6)$ \\
\hline 14-day EBS/14-day Sham & $.84(.05)$ & $.87(.07)$ & $124.1(4.7)$ & $152.6(10.7)$ & $98.7(7.7)$ & $88.2(7.2)$ \\
\hline 28-day EBS (no food deprivation) & $.86(.03)$ & $.92(.03)$ & $164.2(3.4)$ & $207.4(14.0)$ & $88.9(1.4)$ & $70.4(3.8)$ \\
\hline
\end{tabular}

Note-Numbers in parentheses indicate standard error of the mean. $T=$ telencephalon; $B=$ brainstem.

${ }^{*}$ moles/min/g tissue 
Lastly, there was no behavioral evidence to suggest that EBS, as defined in this study, was painful or aversive to the experimental subjects.

Other attempts to avoid the learning vs. arousal design problem have involved modifying cortical arousal by chronic injections of central nervous system (CNS) stimulants, such as strychnine (Le Boeuf \& Peeke, 1969; Stein, 1971). In general, the effect produced has been disruption of maze performance when subjects are tested later in life. The problem with such studies is that neurotoxicity of such agents often is not monitored. This is even more problematic when developmental studies are done, since any neurotoxic effects are then multiplied by the fact that further CNS development is impaired. EBS avoids these problems and eliminates the risk of side effects of the drug being used.

The importance of early exposure to environmental treatments has been emphasized (Rosenzweig, Bennet, \& Diamond, 1972) and, hence, our concern for the subjects' early exposure to EBS. The fact that a significant effect was demonstrated both in telencephalon AChE activity and maze performance for early EBS which was reversible later with continued EBS reinforces the belief that the CNS is not a static tissue but rather has considerable ability to adapt to functional demands. This suggests that either an inhibitory center was being stimulated or that the parameters of stimulation, by producing very frequent, repetitive depolarization of the roticular formation may have inhibited postsynaptic depolarization of the diffuse thalamic projection system.

Our study, using a different technique (EBS), lends support to the postulate of Rosenzweig and Bennett (1969) that AChE activity is positively correlated with maze performance. With this technique, the data suggest that critical periods of development may be an important factor in producing the effect. Our study has also demonstrated the feasibility of using chronically implanted electrodes to study early development. This technique may aid in further elucidation of various critical periods in brain development.

\section{REFERENCE NOTE}

1. Lewis, G. A., Preskorn, S. H., \& Hughes, C. W. Biochemical and behavioral consequences of EBS during early development. Paper presented at the meeting of the Southwestern Psychological Association, San Antonio, Texas, April 1971.

\section{REFERENCES}

Collier, B., \& Murray-Brown, N. Validity of a method measuring transmitter release from the central nervous system. Nature (London), 1968, 218, 484-485.

Denenberg, V. H., Woodcock, J. M., \& Rosenberg, K. M. Longterm effects of preweaning and postweaning free- environment experience on rats problem-solving behavior. Journal of Comparative and Physiological Psychology, 1968. 66. 533.535 .

Ellman, G. L., Courtney, K. D., Androes, V. N., \& Featherstone. R. M. A new and rapid determination of acetylcholinesterase activity. Biochemical Pharmacology, 1961. 7. 88-95.

Forgays. D. G.. \& Forgays. T. W. The nature of the effect of early free-environmental experience in the rat. Journal of Comparative and Physiological Psychology. 1952, 45, 322-328.

Hughes. C. W.. Lewis. G. A., \& Preskorn, S. H. A stereotaxic implant technique for the weanling rat. Behavior Research Methods and Instrumentation. 1973. 5. 283-284.

KANAI. T.. \& SzERB, J. D. The mesencephalic reticular activation system and cortical acetylcholine output. Nature (London), 195. 205. 81.

König, J. F. R., \& Klippel, R. A The rat brain: A stereotaxic atlas. Baltimore: Williams and Wilkins, 1963.

Krech. D.. Rosenzweig. M. R.. \& Bennett, E. L. Relations between brain chemistry and problem-solving among rats raised in enriched and impoverished environments. Journal of Comparative and Physiological Psychology, 1962, 55, 801-807.

Le Boeuf. B. J., \& Peeke. H. V. S. The effect of strychnine administration during development on adult maze learning in the rat. Psychopharmacologia, 1969. 16. 49-53.

Meyer, J. S.. Monvra, F., Sakamoto, K.. \& Kondo, A. Effect of stimulation of the brain-stem reticular formation on cerebral blood flow and oxygen consumption. Electroencephalography and Clinical Neurophysiology, 1969, 28, 125-132.

Moruzzı. G., \& Magoun, H. W. Brain stem reticular formation and activation of the EEG. Electroencephalography and Clinical Neurophysiology, 1949, 1, 455-473.

NeIla NDS, J. B. In S. P. Colwich (Ed.), Methods in enzymology. New York: Academic Press, 1955.

Phillis. J. W. Acetylcholine release from the cerebral cortex: Its role in cortical arousal. Brain Research, 1968, 7. 378-389.

Rosenzweig, M. R., \& Bennett, E. L. Effects of differential environments on brain weights and enzyme activities in gerbils, rats, and mice. Developmental Psychobiology, 1969, 2, 87-95.

Rosenzweig, M. R., Bennett, E. L., \& Diamond, M. C. Brain changes in response to experience. Scientific American, 1972, 226, 22-29.

StEIN, D. G. Effects of strychnine during different periods of development on maze learning in adult rats. Communications in Behavioral Biology, 1971, 6, 335-340.

Thompson, W. R., \& Melzack, R. Early environment. Scientific American, 1956, 194, 38-42.

Webster, K., Sagvolden, T., Saunders, S., \& Monkvik, T. Habituation characteristics and reinforcing effects of brain stem stimulation in unanaesthetised cats. Brain Research, 1974, 79, 363-374.

WINER, B. J. Statistical principles in experimental design (2nd ed.). New York: McGraw-Hill, 1971.

\section{NOTE}

1. One possible explanation for these results is an error in dissection. This is highly unlikely, since all dissections were performed blind. Furthermore, the total brain weight for Group 1 was significantly less than that for Group 2. An error in dissection could account for this finding only if tissue was systematically lost from the entire brains from Group 1 animals. If a critical periodEBS interaction is responsible, the fact that such a difference was not found in the older EBS preparations is remarkable.

(Received for publication September 14, 1977; revision accepted November 17, 1977.) 